\title{
Synthesis of a Binuclear 6-Purinylpalladium(II) Complex and Its Possible Role in Stille Couplings of 6-Chloropurines
}

\author{
Lise-Lotte Gundersen
}

Oslo College, Department of Health, Program of Pharmacy. Pilestredet 52, N-0167 Oslo, Norway

\begin{abstract}
Gundersen, L.-L., 1996. Synthesis of a Binuclear 6-Purinylpalladium(II) Complex and Its Possible Role in Stille Couplings of 6-Chloropurines. - Acta Chem. Scand. 50: 462-465. (C) Acta Chemica Scandinavica 1996.
\end{abstract}

Pd-Catalyzed cross couplings of halopurines with organometallic reagents like organotin, ${ }^{1}$ organozinc, ${ }^{11,1 \mathrm{n}, 2}$ organoaluminium ${ }^{3}$ or Grignard reagents ${ }^{4}$ are valuable reactions for $\mathrm{C}-\mathrm{C}$ bond formation in purines. Similar coupling reactions of simple aryl halides are generally believed to proceed via catalytic cycles initiated by an oxidative addition of an aryl halide to $\operatorname{Pd}(0)$, followed by transmetallation from an organometallic reagent, isomerization and reductive elimination of the coupling product. $^{5}$ A detailed understanding of Pd-catalyzed couplings of halopurines is complicated by the fact that the exact nature of the palladium-purine complexes involved in the reactions is unknown. Complexes formed by oxidative addition of heteroaryl halides to $\mathrm{Pd}(0)$ species have received relatively little attention, ${ }^{6}$ and purine derivatives are not among the heteroarenes studied. However, it is demonstrated that both mononuclear and binuclear complexes might be formed when 2-haloazines or halodiazines are allowed to react with $\mathrm{Pd}\left(\mathrm{PPh}_{3}\right)_{4} \cdot{ }^{6 a, b, d-g}$ Among the factors governing the position of the equilibrium between the monomer and the dimer is the electron donating ability of the nitrogen atoms in the heterocyclic ligand; high basicity of the heterocycle favors formation of the dimer. ${ }^{6 \mathrm{~g}}$ To the best of our knowledge the role that this class of binuclear palladium-heterocycle complexes may play in Pd-catalyzed couplings of heteroaryl halides has never been investigated. Binuclear complexes with the general structure (PdLXAr) $)_{2}$ have recently been reported to be involved in Pd-catalyzed amination of simple aryl halides. $^{7}$ In this communication we report the first study of complexes formed from oxidative addition of a halopurine to $\operatorname{Pd}(0)$, and their possible role in $\mathrm{Pd}$-catalyzed couplings.

9-Benzyl-6-chloropurine $\mathbf{1}^{11}$ was reacted with
$\mathrm{Pd}\left(\mathrm{PPh}_{3}\right)_{4}$ in 1,2-dichloroethane (DCE) at $70^{\circ} \mathrm{C}$ for $4 \mathrm{~h}$, to give a ca. 9:1 mixture of the monomer 2 and dimer 3 as judged by the NMR spectra of the crude product (Scheme 1).

The ${ }^{31} \mathrm{P}$ NMR spectrum of crude product indicated that the mononuclear complex 2 had the expected trans geometry. The equivalent phosphorus atoms in the compound 2 resonated as a singlet $(22.8 \mathrm{ppm}$ relative to $\mathrm{H}_{3} \mathrm{PO}_{4}$ ), whereas a doublet of doublets would be expected for the phosphorus atoms in the cis isomer. ${ }^{\text {th }}$ No attempt was made to isolate the monomer 2 owing to its susceptibility to dimerization. The crude mixture of the complexes 2 and 3 was treated with $\mathrm{H}_{2} \mathrm{O}_{2}$ in 1,2-dichloroethane in order to oxidize the free $\mathrm{PPh}_{3}$ and shift the monomer-dimer equilibrium completely towards the dimer. ${ }^{6 g}$ After the oxidation, the binuclear complex 3 could be isolated in $70 \%$ yield.

The dimer 3 was reacted with triphenylphosphine (2 equiv.) in DMF- $d_{7}$ or $\mathrm{CD}_{2} \mathrm{Cl}_{2}$ at ambient temperature, and the reaction was followed by ${ }^{31} \mathrm{P}$ NMR spectroscopy. The monomeric complex 2 formed slowly, and oxidation of triphenylphosphine to triphenylphosphine oxide was also observed. When all the dimer 3 and free triphenylphosphine was consumed, a slow dimerization of the monomer 2 back to the dimer 3 was observed.

Having established that both the binuclear complex 3 and the mononuclear complex 2 are formed after reaction between $\mathrm{Pd}\left(\mathrm{PPh}_{3}\right)_{4}$ and the 6-chloropurine 1, the reactivity of the complex 3 towards organotin reagents was examined. The complex 3 was reacted with tributyl(vinyl) tin 4a (2 equiv.) in DCE at $70^{\circ} \mathrm{C}$ (Scheme 2). After $3.5 \mathrm{~h}$, almost all the tin reagent was consumed, but only ca. $14 \%$ 6-vinylpurine $\mathbf{5 a}^{11}$ was formed as judged by the ${ }^{1} \mathrm{H}$ NMR spectrum. At this time, the formation of $\mathrm{Pd}(\mathrm{s})$ could be observed and ${ }^{31} \mathrm{P}$ NMR showed that $\mathrm{Ph}_{3} \mathrm{PO}$ was formed. 
<smiles>Clc1ncnc2c1ncn2Cc1ccccc1</smiles>

1

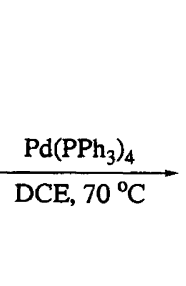<smiles></smiles>

2

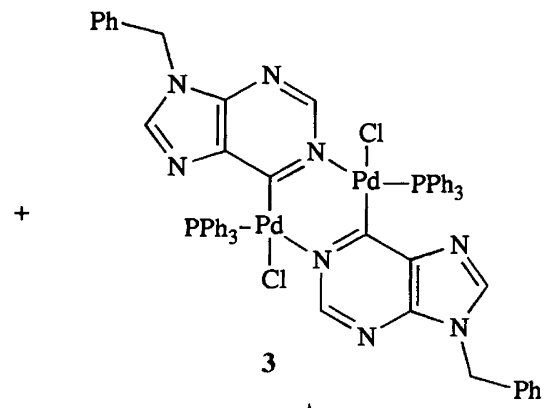

$\mathrm{H}_{2} \mathrm{O}_{2}$, DCE

Scheme 1

\section{Scheme 2}

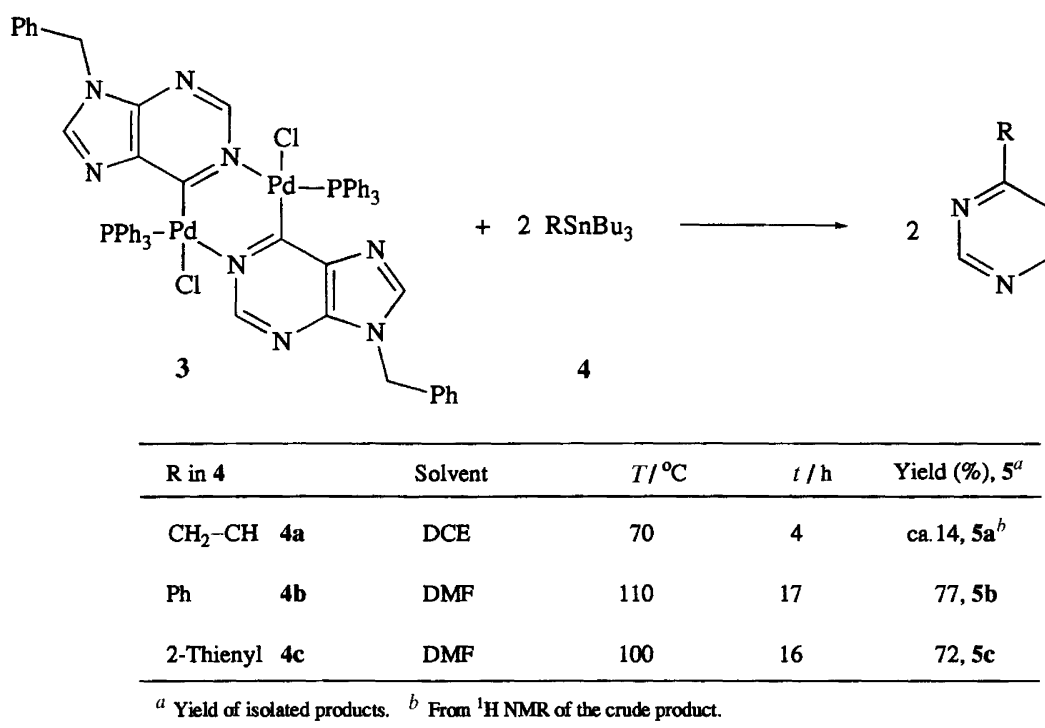

No $\mathrm{PPh}_{3}$ or monomer 2 could be detected. Increasing the amount of the tin reagent to 10 equiv. did not result in a significant increase in the yield of $\mathbf{5 a}$, and only traces of the vinylpurine was formed when the reaction was performed in DMF at various temperatures.

The reactivity of the complex 3 towards tin reagents appears to be highly dependent on the nature of the organostannane. Almost all the complex 3 was converted to the 6-arylpurines $\mathbf{5 b}$ and $\mathbf{5 c},{ }^{11}$ when reacted with 2 equiv. of the aryl(tributyl)tin reagents $\mathbf{4 b}$ and $\mathbf{4 c}$ in DMF overnight. The products $\mathbf{5 b}$ and $\mathbf{5 c}$ were isolated in high yields. These results show that the binuclear $\mathbf{P d}$ complex 3 is capable of reacting with organotin reagents to form the compounds 5 , and that both purine ligands in the dimer 3 can be converted to the coupling product. The reactions were performed without the addition of triphenylphosphine, and the complex $\mathbf{3}$ is completely stable for weeks in the solvents used. Hence it can be ruled out that the dimer 3 is in equilibrium with the monomer 2 and that the latter complex is the actual participant in the transmetallation, at least initially. To our knowledge, these are the first examples of trans- metallation reactions of this class of binuclear $\mathrm{Pd}$ complexes.

Finally, the ability of the binuclear Pd complex 3 to catalyze cross couplings between the 6-chloropurine 1 and organostannanes 4 was examined (Scheme 3 ). The coupling with tributyl(vinyl)tin $\mathbf{4 a}$ in the presence of 5 mol \% of 3 in refluxing DCE was sluggish. After $3.5 \mathrm{~h}$ the organotin reagent was consumed, but only ca. $15 \%$ of the vinylpurine 5a was formed, as judged by ${ }^{1} \mathrm{H}$ NMR spectroscopy. Compound 5a has previously been isolated in high yield when $\left(\mathrm{Ph}_{3} \mathrm{P}\right)_{2} \mathrm{PdCl}_{2}$ was used as a catalyst under otherwise identical reaction conditions. ${ }^{11}$ On the other hand, the coupling between the chloropurine 1 and the arylstannanes $\mathbf{4 b}$ and $\mathbf{4 c}$ proceeded essentially to completion in the presence of $5 \mathrm{~mol} \%$ of 3 , and the isolated yields of the coupling products $5 \mathbf{5 b}$ and $\mathbf{5 c}$ were comparable with those obtained when $\left(\mathrm{Ph}_{3} \mathrm{P}\right)_{2} \mathrm{PdCl}_{2}$ was employed as catalyst. ${ }^{11}$

This communication constitutes the first study of complexes formed after oxidative addition of a halopurine to $\operatorname{Pd}(0)$, and the results described herein demonstrate that binuclear Pd complexes such as $\mathbf{3}$ undergo trans- 


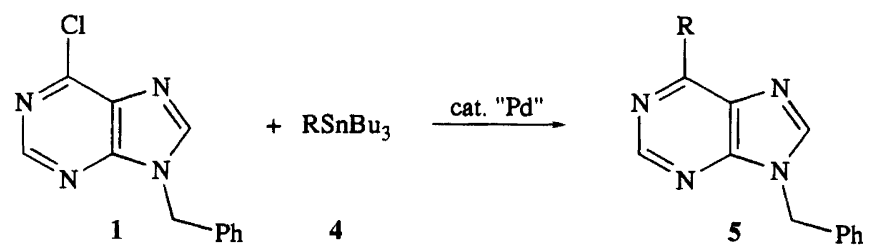

\begin{tabular}{|c|c|c|c|c|c|c|}
\hline$R$ in 4 & & "Pd" & Solvent & $T /{ }^{\circ} \mathrm{C}$ & $t / \mathrm{h}$ & Yield (\%), $\mathbf{5}^{a}$ \\
\hline $\mathrm{CH}_{2}=\mathrm{CH}$ & $4 a$ & 3 & DCE & $\Delta$ & 4 & $\mathrm{ca} .15, \mathbf{5} \mathbf{a}^{b}$ \\
\hline $\mathrm{CH}_{2}=\mathrm{CH}$ & $4 \mathbf{a}$ & $\left(\mathrm{Ph}_{3} \mathrm{P}\right)_{2} \mathrm{PdCl}_{2}$ & DCE & $\Delta$ & 4 & $87,5 \mathbf{a}^{c}$ \\
\hline $\mathrm{Ph}$ & $4 b$ & 3 & DMF & 110 & 7 & $78,5 b$ \\
\hline $\mathrm{Ph}$ & $4 b$ & $\left(\mathrm{Ph}_{3} \mathrm{P}\right)_{2} \mathrm{PdCl}_{2}$ & $\mathrm{DMF}$ & 110 & 7 & $75, \mathbf{5 b}^{c}$ \\
\hline 2-Thienyl & $4 \mathbf{c}$ & 3 & DMF & 100 & 16 & $91, \mathbf{5 c}$ \\
\hline 2-Thienyl & $4 c$ & $\left(\mathrm{Ph}_{3} \mathrm{P}\right)_{2} \mathrm{PdCl}_{2}$ & $\mathrm{DMF}$ & 100 & 16 & $87,5 c^{c}$ \\
\hline
\end{tabular}

Scheme 3

metallation with organotin reagents and catalyze Stille couplings. Such binuclear complexes might be real intermediates in Pd-catalyzed coupling reactions.

\section{Experimental}

The ${ }^{1} \mathrm{H}$ NMR spectra were recorded at $300 \mathrm{MHz}$ with a Varian XL-300, or at $200 \mathrm{MHz}$ with a Varian Gemini 200 or a Bruker Avance DPX 200 instrument. The ${ }^{13} \mathrm{C}\left\{{ }^{1} \mathrm{H}\right\}$ NMR spectra were recorded at $75 \mathrm{MHz}$ or $50 \mathrm{MHz}$ with the same instruments.

${ }^{31} \mathrm{P}\left\{{ }^{1} \mathrm{H}\right\}$ NMR spectra were recorded at $121 \mathrm{MHz}$ using the above mentioned Bruker instrument. 1,2Dichloroethane was distilled from $\mathrm{CaH}_{2}$ and DMF from $\mathrm{BaO}$. 9-Benzyl-6-chloro-9H-purine ${ }^{11}$ and 2-(tributylstannyl)thiophene ${ }^{8}$ was prepared as described before. All other reagents were commercially available and used as received.

Synthesis of the binuclear complex 3 . Triphenylphosphine $(839 \mathrm{mg}, \quad 3.2 \mathrm{mmol})$ and $\mathrm{Pd}_{2} \mathrm{dba}_{3} \cdot \mathrm{CHCl}_{3}(414 \mathrm{mg}$, $0.4 \mathrm{mmol})$ in dry dichloroethane $(50 \mathrm{ml})$ was stirred at ambient temperature under $\mathrm{N}_{2}$ for $10 \mathrm{~min}$. 9-Benzyl-6chloro- $9 \mathrm{H}$-purine $(196 \mathrm{mg}, 0.8 \mathrm{mmol})$ was added and the reaction mixture was stirred at $70^{\circ} \mathrm{C}$ for $4 \mathrm{~h}$ and concentrated to a small volume in vacuo.

The residue was washed with diethyl ether and dissolved in dichloroethane $(30 \mathrm{ml}) . \mathrm{H}_{2} \mathrm{O}_{2}(35 \%, 1.0 \mathrm{ml})$ was added. The mixture was stirred at ambient temperature for $2 \mathrm{~h}$, dried $\left(\mathrm{Na}_{2} \mathrm{SO}_{4}\right)$ and concentrated to a yellow foam. The residue was washed with diethyl ether and dissolved in a minimum amount of dichloromethane. Methanol $(20 \mathrm{ml})$ was added and the solution was concentrated in vacuo until precipitation began. The resulting mixture was kept at $-4^{\circ} \mathrm{C}$ overnight. The product was filtered off, washed with diethyl ether and dried in vacuo; yield $344 \mathrm{mg} \quad(70 \%)$, powdery yellow crystals. M.p. $229-231^{\circ} \mathrm{C}$ (dec.). ${ }^{1} \mathrm{H}$ NMR $\left(200 \mathrm{MHz}, \mathrm{CD}_{2} \mathrm{Cl}_{2}\right)$ : $\delta 4.90\left(\mathrm{~d}, J 15 \mathrm{~Hz}, 2 \mathrm{H}, \mathrm{H}_{\mathrm{A}}, \mathrm{CH}_{2}\right), 5.07(\mathrm{~d}, J 15 \mathrm{~Hz}, 2$ $\mathrm{H}, \mathrm{H}_{\mathrm{B}}, \mathrm{CH}_{2}$ ), 7.0-7.3 (m, $\left.28 \mathrm{H}, \mathrm{Ph}\right), 7.58$ (s, $\left.2 \mathrm{H}, \mathrm{H}-8\right)$, 7.8-7.9 (m, $12 \mathrm{H}, \mathrm{Ph}), 8.70$ (s, $2 \mathrm{H}, \mathrm{H}-2) .{ }^{13} \mathrm{C}\left\{{ }^{1} \mathrm{H}\right\}$ NMR $\left(75 \mathrm{MHz}, \mathrm{CD}_{2} \mathrm{Cl}_{2}\right): \delta 47.2\left(\mathrm{CH}_{2}\right), 128-131(\mathrm{Ph}), 135-136$ $(\mathrm{Ph}), 140.7,142.8,143.4,152.3,193.9 .{ }^{31} \mathrm{P}\left\{{ }^{1} \mathrm{H}\right\}$ NMR (121 $\mathrm{MHz}, \mathrm{CD}_{2} \mathrm{Cl}_{2}$ ): $\delta 28.08$.

General procedure for the reaction of the dimer 3 with organotin reagents. The dimer $3(0.17 \mathrm{mmol})$ and the organostannane $2(0.34 \mathrm{mmol})$ was reacted as shown in Scheme 2. The reaction mixture was evaporated, and the product 5 was isolated as reported earlier. ${ }^{11}$

General procedure for the coupling of 9-benzyl-6chloro-9H-purine with organotin reagents. The 6-chloropurine $1(0.5 \mathrm{mmol})$ was reacted with organostannane 4 $(0.7 \mathrm{mmol})$ in the presence of the dimer $3(0.02 \mathrm{mmol})$ under the same conditions as reported earlier. ${ }^{11}$

Acknowledgment. The Norwegian Research Council is greatly acknowledged for financing the Bruker Avance DPX 200 instrument at the Department of Chemistry, University of Oslo, Norway.

\section{References}

1. (a) Nair, V., Turner, G. A. and Chamberlain, S. D. J. Am. Chem. Soc. 109 (1987) 7223. (b) Nair, V., Turner, G. A., Buenger, G. S. and Chamberlain, S. D. J. Org. Chem. 53 (1988) 3051. (c) Nair, V. and Buenger, G. S. J. Am. Chem. Soc. 111 (1989) 8502. (d) Nair, V., Purdy, D. F. and Sells, T. B. J. Chem. Soc., Chem. Commun. (1989) 878. (e) Nair, V. Nucleosides Nucleotides 8 (1989) 699. (f) Nair, V. and Lyons, A. G. Tetrahedron 46 (1990) 7677. (g) Moriarty, R. M., Epa, W. R. and Awasthi, A. K. Tetrahedron Lett. 31 (1990) 5877. (h) Nair, V. and Purdy, D. F. Tetrahedron 47 
(1991) 365. (i) Mamos, P., Van Aerschot, A. A., Weyns, N. J. and Herdewijn, P. A. Tetrahedron Lett. 33 (1992) 2413.

(j) Van Aerschot, A. A., Mamos, P., Weyns, N. J., Ikeda, S., De Clercq, E. and Herdewijn. P. A. J. Med. Chem. 36 (1993) 2938. (k) Gundersen, L.-L. Tetrahedron Lett. 35 (1994) 3155. (1) Gundersen, L.-L., Bakkestuen, A. K., Aasen, A. J., Øverås, H. and Rise, F. Tetrahedron 50 (1994) 9743. (m) Nagatsugi, F., Uemura, K., Nakashima, S., Maeda, M. and Sasaki, S. Tetrahedron Lett. 36 (1995) 421. (n) Gundersen, L.-L., Langli, G. and Rise, F. Tetrahedron Lett. 36 (1995) 1945. (o) Ozola, V., Persson, T., Gronowitz, S. and Hörnfeldt, A.-B. J. Heterocycl. Chem. 32 (1995) 863.

2. Gundersen, L.-L. Acta Chem. Scand. 50 (1996) 58.

3. Hirota, K., Kitade, Y., Kanbe, Y. and Maki, Y. J. Org. Chem. 57 (1992) 5268.

4. (a) Co̊ng-Danh, N., Beaucourt, J.-P. and Pichat, L. Tetrahedron Lett. (1979) 3159. (b) Bergstrom, D. E. and Reday, P. A. Tetrahedron Lett. 23 (1982) 4191.

(c) Sugimura, H. and Takei, H. Bull. Chem. Soc. Jpn. 58 (1985) 664.

5. See for instance: Amatore, C., Jutand, A. and Suarez, A. J. Am. Chem. Soc. 115 (1993) 9531, and references therein.

6. See for instance: (a) Nakatsu, K., Kinoshita, K., Kanda, H., Isobe, K., Nakamura, Y. and Kawaguchi, S. Chem. Lett.
(1980) 913 (b) Isobe, K., and Kawaguchi, S. Heterocycles 16 (1981) 1603. (c) Yamamoto, Y. and Yanagi, A. Chem. Pharm. Bull. 30 (1982) 2003. (d) Mantovani, A. and Crociani, B. J. Organomet. Chem. 236 (1982) C37. (e) Crociani, B., Di Bianca, F., Giovenco, A. and Scrivanti, A. J. Organomet. Chem. 251 (1983) 393. (f) Crociani, B., Di Bianca, F., Giovenco, A. and Scrivanti, A. J. Organomet. Chem. 291 (1985) 259. (g) Bertani, R., Berton, A., Di Bianca, F. and Crociani, B. J. Organomet. Chem. 303 (1986) 283. (h) Urata, H., Tanaka, M. and Fuchikami, T. Chem. Lett. (1987) 751. (i) Benneche, T. Acta Chem. Scand. 44 (1990) 927.

7. (a) Paul, F., Patt, J. and Hartwig, J. F. J. Am. Chem. Soc. 116 (1994) 5969. (b) Guram, A. S. and Buchwald, S. L. J. Am. Chem. Soc. 116 (1994) 7901. (c) Hartwig, J. F. and Paul, F. J. Am. Chem. Soc. 117 (1995) 5373. (d) Paul, F., Patt, J. and Hartwig, J. F. Organometallics 14 (1995) 3030. (e) Louie, J. and Hartwig, J. F. Tetrahedron Lett. 36 (1995) 3609. (f) Guram, A. S., Rennels, R. A. and Buchwald, S. L. Angew. Chem. Int. Ed. Engl. 34 (1995) 1348.

8. Pinhey, J. T. and Roche, E. G. J. Chem. Soc., Perkin Trans. 1 (1988) 2415.

Received September 11, 1995. 